\title{
Tendência das taxas de homicídio em Santa Catarina por microrregiões: 1996 a 2019
}

\section{Daniel Bando ${ }^{1}$, Mariana Garcia ${ }^{1}$ and Jane Friestino ${ }^{2}$}

Resumo

Contexto: O homicídio é um problema de segurança e de saúde pública. O objetivo desse trabalho foi avaliar as tendências das taxas de homicídio por microrregiões no estado de Santa Catarina. Trata- se de um estudo ecológico de séries temporais. Métodos: Os dados foram coletados pelo Departamento de Informática do Sistema Único de Saúde e pelo Censo Nacional. Foi utilizada a técnica de regressão linear segmentada, para estimar as variações percentuais anuais (VPA) com intervalo de confiança de $95 \%$ e possíveis pontos de inflexão pelo software joinpoint. Resultados: no período estudado ocorreram 16408 homicídios em Santa Catarina, correspondente a uma taxa de 11,3 casos por 100 mil habitantes. De 2003 a 2017 houve tendência de aumento do homicídio com VPA de $+1,28$. As microrregiões a seguir apresentaram tendência de aumento em mais da metade do período de estudo: Araranguá, Blumenau, Chapecó, Criciúma, Itajaí Ituporanga - Tijucas, Tabuleiro. Em oposição, as microrregiões de Florianópolis, Curitibanos, Canoinhas apresentaram tendência de diminuição; as demais mantiveram-se estáveis. Conclusões: $38,9 \%$ das áreas de estudo apresentaram tendência de aumento das taxas de homicídio, 16,7\% apresentaram tendência de diminuição e 44,4\% permaneceram estáveis.

\section{Keywords}

homicide, spatiotemporal analysis, public health, violence

\section{INTRODUÇÃO}

O homicídio é um conhecido problema de saúde e de segurança pública (Cardoso, Cecchetto, Corrêa, \& Souza, 2016). Trata-se de um fenômeno complexo e multifatorial. Tem custos emocionais e sociais de grande magnitude, pode levar à ruptura de famílias, afetar amigos das vítimas, causar sofrimento,

\footnotetext{
${ }^{1}$ Universidade Federal de Alfenas, Alfenas, Minas Gerais, Brasil

2 Universidade Federal da Fronteira Sul, Chapecó, Santa Catarina, Brasil

Emails: daniel.bando@unifal-mg.edu.br (Daniel Bando), marianarangel01@gmail.com (Mariana Garcia), jane.friestino@uffs.edu.br (Jane Friestino)
} 
revolta, medo e desespero (Reichenheim et al., 2011). De acordo com a Organização Mundial da Saúde (OMS) em 2019 ocorreram 477 mil homicídios no mundo, o que corresponde a uma taxa global 6,2 por 100 mil habitantes (WHO, 2019). No entanto a média oculta profundas variações. Enquanto El Salvador, Honduras e Venezuela apresentam taxas que variam de 63,6 a 85,0 por 100 mil, Portugal, Eslovênia e China apresentam taxas inferiores a 1,0 por 100 mil. O Brasil ocupa a $11^{\text {a }}$ posição do ranking com 32,6 homicídios por 100 mil (WHO, 2019). No Brasil as taxas de homicídio dos 27 estados variaram de 13,0 em Santa Catarina a 68,9 em Alagoas (Bando \& Lester, 2014).

A arma de fogo foi o principal meio utilizado no mundo, em 2016 ocorreram 251 mil homicídios por arma de fogo, sendo o Brasil, Estados Unidos, México, Colômbia, Venezuela e Guatemala responsáveis por 50,5\% dessas mortes (The Global Burden of Disease Injury Collaborators, 2018). De acordo com estimativas da United Nations Office on Drugs and Crime (UNODC, 2019) cerca de 90\% das vítimas por homicídios no mundo são homens, sendo o maior risco na faixa etária de 15 a 29 anos e cerca de $19 \%$ da carga total de homicídios estava relacionada ao crime organizado em 2017. Um estudo de revisão sobre homicídio no Brasil revelou que o Brasil parece seguir o padrão mundial. O perfil epidemiológico da violência homicida no país correspondeu aos jovens do sexo masculino, na faixa etária dos 15 a 29 anos, negros, moradores nas periferias das cidades ou favelas. Com relação às condições de vida, destacou-se a população com elevado nível de vulnerabilidade devido à falta de oportunidade social e disputas territoriais ligadas ao tráfico de drogas (Oliveira, Luna, \& Silva, 2020; Reichenheim et al., 2011). No Brasil, o homicídio relaciona-se também com as áreas da fronteira agrícola e conflitos pela posse de terra (Reichenheim et al., 2011). Na cidade de São Paulo, estudo ecológico também sugere associação dos homicídios com a violência policial (M. F. T. Peres, Cardia, Neto, Santos, \& Adorno, 2008). Quanto aos fatores de risco individuais, incluem transtornos relacionados ao uso de drogas, transtornos de personalidade e falta de aderência ao tratamento psiquiátrico (Valença \& Moraes, 2006).

A taxa global de homicídio, de 1993 a 2017, diminuiu de 7,4 para 6,1 por 100 mil (UNODC, 2019). Porém, essa tendência de diminuição mundial pode ocultar, novamente, diferentes tendências temporais em várias localidades do globo. No Brasil, as taxas aumentaram de 11,7 por 100 mil em 1980, para 28,9 por 100 mil em 2003. Posteriormente houve uma oscilação, atingiu a marca de 26,2 por $100 \mathrm{mil} \mathrm{em} 2010$ e voltou a aumentar nos últimos anos chegando a 32,6 por 100 mil ( ; WHO, 2019) (Murray, Cerqueira, \& Kahn, 2013). Estudo ecológico sobre tendências do homicídio no Brasil revelou que de 2000 a 2015 houve aumento de 6\% das taxas. Esse estudo também analisou as tendências de acordo com o porte populacional dos municípios, e no estado de Santa Catarina houve aumento nos três grupos analisados: municípios de pequeno, médio e grande porte (Soares Filho et al., 2020). O presente estudo tem como objetivo verificar a tendência das taxas de homicídio por microrregião no estado de Santa Catarina.

\section{METODOLOGIA}

\section{Área de estudo}

O estado de Santa Catarina faz parte da região sul do Brasil (Figura 1A), possui 295 municípios agrupados em 20 microrregiões (Figura 1B). Possuiu colonização predominante europeia, sobretudo alemã, italiana e açoriana, entretanto, isso fez parte de um processo de reapropriação do território, se fazendo importante lembrar que em determinadas regiões como no oeste catarinense merece destaque a presença de caboclos e indígenas (Souza, Bernardi, \& Santos, 2020). O estado apresenta uma área territorial de $95.730,7 \mathrm{~km}^{2}$, 
a menor da região sul do Brasil. A população estimada do estado para 2020 foi de 7.252 .502 habitantes (84\% rural) e densidade demográfica de 65,27 hab $/ \mathrm{km}^{2}$ (Ibge, 2021).

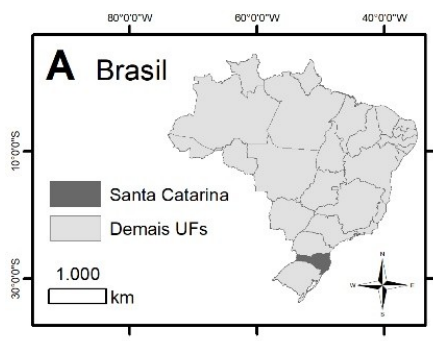

\begin{tabular}{|c|l|}
\hline 1 & SÃO MIGUEL DO OESTE \\
\hline 2 & CHAPECÓ \\
\hline 3 & XANXERÊ \\
\hline 4 & JOAÇABA \\
\hline 5 & CONCÓRDIA \\
\hline 6 & CANOINHAS \\
\hline 7 & SÃO BENTO DO SUL \\
\hline 8 & JOINVILLE \\
\hline 9 & CURITIBANOS \\
\hline 10 & CAMPOS DE LAGES \\
\hline 11 & RIO DO SUL \\
\hline 12 & BLUMENAU \\
\hline 13 & ITAJAÍ \\
\hline 14 & ITUPORANGA \\
\hline 15 & TIJUCAS \\
\hline 16 & FLORIANÓPOLIS \\
\hline 17 & TABULEIRO \\
\hline 18 & TUBARÃO \\
\hline 19 & CRICIÚMA \\
\hline 20 & ARARANGUÁ \\
\hline
\end{tabular}
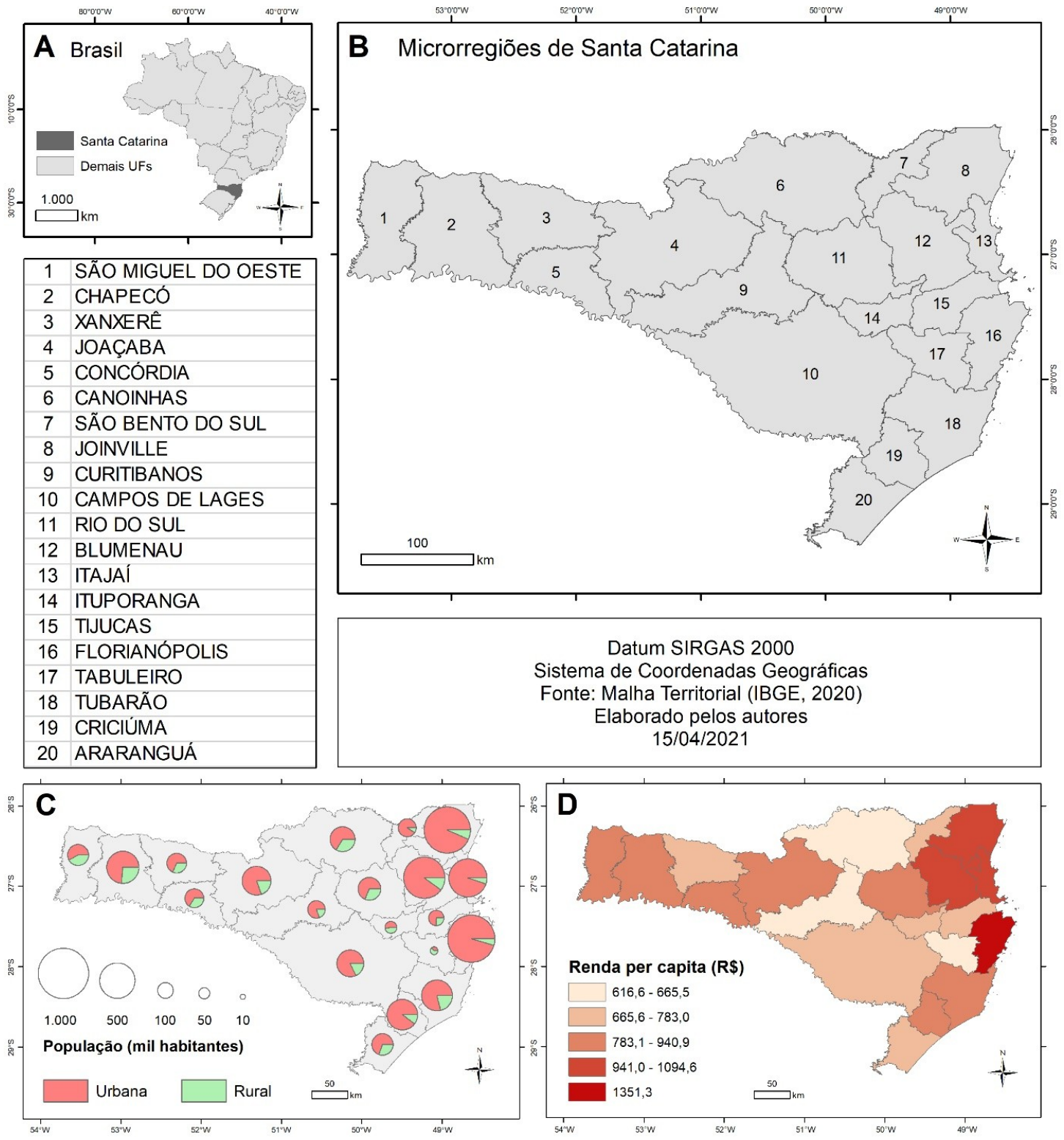

Figure 1. Mapa de localização do estado de Santa Catarina por microrregiões e características sociodemográficas 
As microrregiões mais populosas localizam-se à nordeste, no litoral catarinense, como Florianópolis e Joinville, com população acima de 840 mil habitantes cada, seguidos por Blumenau e Itajaí. Nota-se também que a população urbana nessas áreas é alta, acima de 90\% (Figura 1C). Tabuleiro e Ituporanga, as microrregiões menos populosas, também apresentaram os menores percentuais da população urbana, 35,6 e 52,5\%, respectivamente. Tirando os extremos, as demais microrregiões apresentaram em média $74,8 \%$ da população em situação urbana. A renda per capita em Santa Catarina no último censo foi R\$ 967. Quanto à distribuição desse indicador, nota-se que a concentração é maior nas microrregiões mais populosas, com a máxima em Florianópolis ( $\mathrm{R}$ \$ 1.351), seguidos por Blumenau, Joinville e Itajaí, com renda superior a R\$ 1.000 (Figura 1D). Tabuleiro que faz fronteira com Florianópolis, contrasta com a renda de $\mathrm{R} \$$ 665. Canoinhas e Curitibanos na região central compõem as microrregiões com as menores rendas. Nas áreas da região oeste (São Miguel Oeste, Chapecó, Concórdia), assim como à sudeste (Criciúma e Tubarão) apresentaram renda próximo à média do estado, variando de $\mathrm{R} \$ 783$ a $\mathrm{R} \$$ 940 .

\section{Desenho do estudo}

Trata-se de um estudo ecológico de séries temporais sobre o homicídio no estado de Santa Catarina, onde foram usados dados agregados por microrregião. Dados de mortalidade foram extraídos do Sistema de Informação sobre Mortalidade (SIM), disponibilizados pelo Departamento de Informática do Sistema Único de Saúde, sendo um dado oficial do Ministério da Saúde (Datasus, 2021). As mortes por homicídio correspondem aos códigos "X85 a Y09 - agressões" de acordo com a Décima Classificação Internacional de Doenças (CID-10). Os dados sociodemográficos foram extraídos do censo nacional do IBGE (Ibge, 2010). Foram calculadas as taxas homicídio ajustadas por idade, pelo método direto. A população de referência foi a da Organização Mundial da Saúde (Ahmad et al., 2001). Todos dos dados utilizados são de acesso livre.

\section{Análise}

A análise de tendência foi realizada calculando a variação percentual anual (VPA) usando o Joinpoint Regression Program 4.7.0 (National Cancer Institute, 2019). O programa utiliza o método de regressão de Poisson log-linear que aplica o teste de permutação de Monte Carlo para identificar pontos onde a linha de tendência muda significativamente em magnitude ou direção. O Joinpoint tem sido usado em estudos epidemiológicos para avaliar tendências temporais de vários desfechos como suicídio (Bando et al., 2021) e homicídio (Cardoso et al., 2016). A análise começa com o número mínimo de pontos de junção (zero, que é uma linha reta) e testa se um ou mais pontos de junção são estatisticamente significativos e devem ser adicionados ao modelo. Para este estudo, os parâmetros selecionados foram: método Grid Search (os pontos de junção ocorrem exatamente nas observações), duas observações mínimas entre pontos de junção e no máximo cinco pontos de junção por análise. A VPA e o intervalo de confiança (IC) de 95\% foram estimados para os segmentos de tempo em ambos os lados dos pontos de inflexão. O Joinpoint não processa a análise quando a variável dependente é nula em algum ano da série. As microrregiões Ituporanga, Tijucas e Tabuleiro são as menos populosas (2,8\% do total) e não apresentaram casos de homicídio em 1998. Tabuleiro apresentou valores nulos em outros seis anos da série. Por esse motivo e por serem áreas adjacentes, essas três microrregiões foram agrupadas e o período de análise foi de 1999 a 2019. Foram elaborados mapas temáticos para caracterização da área do estudo com os métodos 
corocromático, coroplético e das figuras geométricas proporcionais (Martinelli, 2013). Foi utilizado o sistema de informação geográfica ArcGIS 10.6 para a elaboração dos mapas.

\section{RESULTADOS E DISCUSSÃO}

No período estudado ocorreram 16.408 homicídios em Santa Catarina, correspondente a uma taxa de 11,3 casos por 100 mil habitantes. De 2003 a 2017 houve aumento significativo da taxa de homicídio com variação percentual anual (VPA) de $+1,28$. Esse intervalo corresponde a $60 \%$ do período estudado. Os gráficos a seguir representam as análises de tendência das taxas de homicídio (Figura 2 a Figura 4). Os pontos representam o dado observado, a linha em negrito a tendência de aumento ou diminuição, e a linha cinza estabilidade. As microrregiões Blumenau, Tubarão, Araranguá e Ituporanga-TijucasTabuleiro apresentaram tendência de aumento em todo período. A velocidade de aumento foi maior em Ituporanga-Tijucas-Tabuleiro, com VPA $=+5,4$, seguido por Tubarão (Tabela 1). Chapecó apresentou tendência de aumento até 2016, e uma queda brusca até 2019. Criciúma apresentou tendência de aumento até $2015(\mathrm{VPA}=+7,4)$, posteriormente permaneceu estável.

Os gráficos a seguir apresentam as tendências das taxas de homicídio para seis microrregiões (Figura 3). Canoinhas e Curitibanos apresentaram tendência de diminuição em todo período, com VPA de -1,5 e -2,3 (Tabela 1), respectivamente. Joinville apresentou tendência de diminuição no final do período, a partir de 2016. Itajaí apresentou tendência de aumento com um pico em 2010, seguido por tendência de queda com menor intensidade. Florianópolis apresentou aumento abrupto com pico em 2003, seguido por diminuição até 2015 e diminuição acentuada no final do período.

A seguir, as microrregiões que não apresentaram tendência, ou seja, mantiveram-se estáveis (Figura 4). Todas apresentaram apenas um segmento de reta. Nota-se que a dispersão dos pontos foi maior. Rio do Sul apresentou o maior VPA $(+1,2)$, mas não foi estatisticamente significativo (Tabela 1$)$.

O mapa a seguir sintetiza os principais resultados da análise de tendência nas microrregiões de Santa Catarina (Figura 5). Foram consideradas tendência de aumento ou diminuição as microrregiões que apresentaram VPN estatisticamente diferente de zero, durante no mínimo 50\% do período do estudo. Em 38,8\% das áreas foi identificado tendência de aumento, inclui Chapecó e as microrregiões do litoral catarinense, com exceção de Joinville e Florianópolis. Essa última, Canoinhas e Curitibanos apresentaram tendência de diminuição (16,6\% das microrregiões). As demais microrregiões $(44,4 \%)$ apresentaram estabilidade.

Portanto em Santa Catarina 83,2\% das microrregiões apresentaram tendência de aumento ou permaneceram estáveis. $\mathrm{O}$ que chama a atenção inicialmente é a associação das tendências de aumento com as microrregiões mais populosas, com maior percentual de população urbana e de maior renda como Blumenau e Itajaí. No entanto a relação não é tão simples, as microrregiões Tabuleiro, Ituporanga e Tabuleiro possuem em média $45,6 \%$ da população em situação rural e apresentou uma tendência de aumento acima da média $(\mathrm{VPN}=+5,4)$. Florianópolis apesar do predomínio de diminuição, apresentou forte oscilação e uma queda abrupta nos últimos anos. De acordo com os dados do censo demográfico do IBGE, entre 2000 e 2010, o percentual da população em situação urbana aumentou em todas microrregiões de Santa Catarina, em diferentes amplitudes (Ibge, 2010). A média do aumento foi de 5,8\%, com a mínima de $0,3 \%$ em Florianópolis e a máxima em Tijucas $(12,2 \%)$. Nas três microrregiões que apresentaram tendência de diminuição do homicídio (Florianópolis, Canoinhas, Curitibanos) o incremento da população urbana no período intercensitário foi abaixo da média. Dentre 

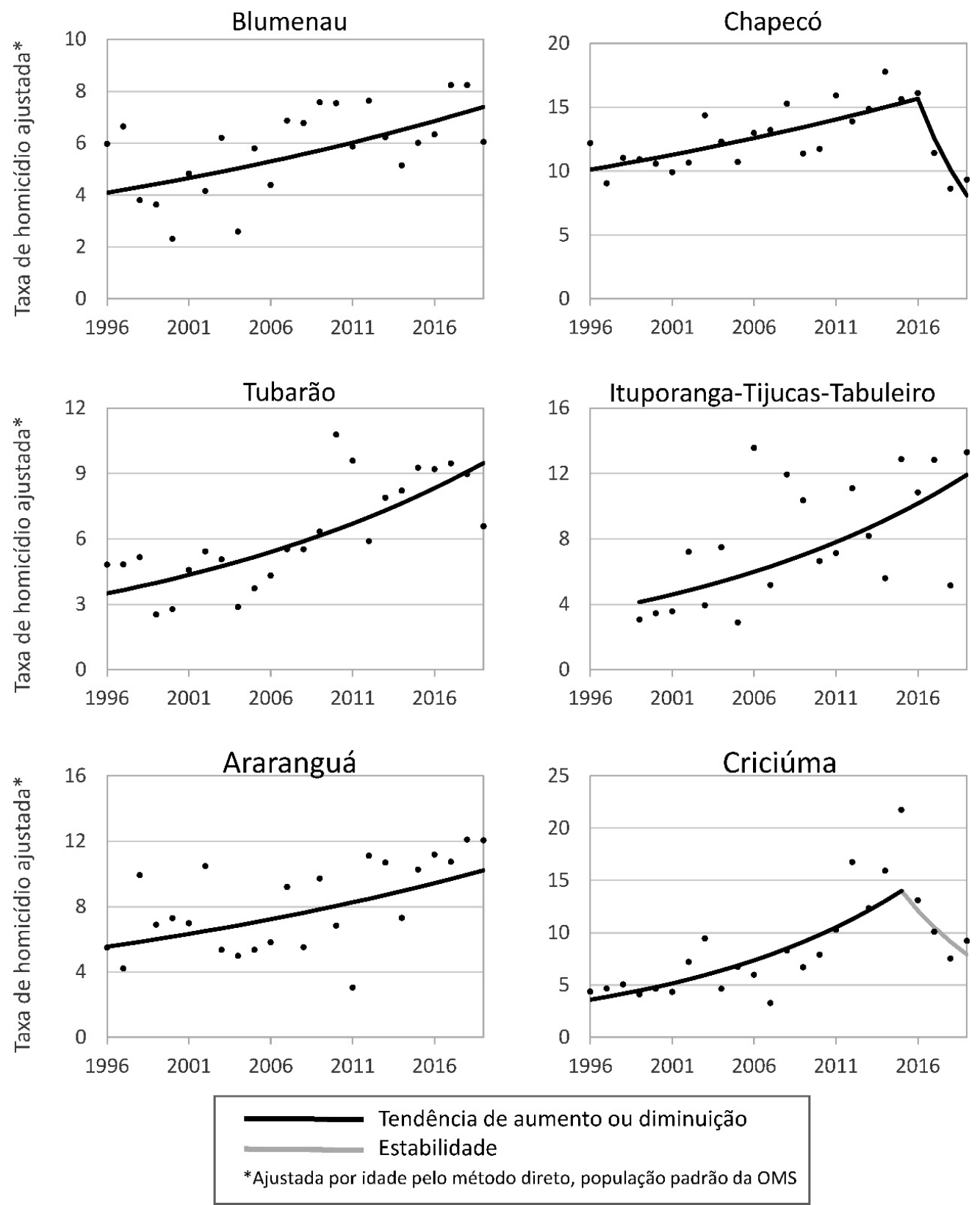

Figure 2. Tendência das taxas de homicídio nas microrregiões: Blumenau, Chapecó, Tubarão, Ituporanga-Tijucas-Tabuleiro, Araranguá, Criciúma 

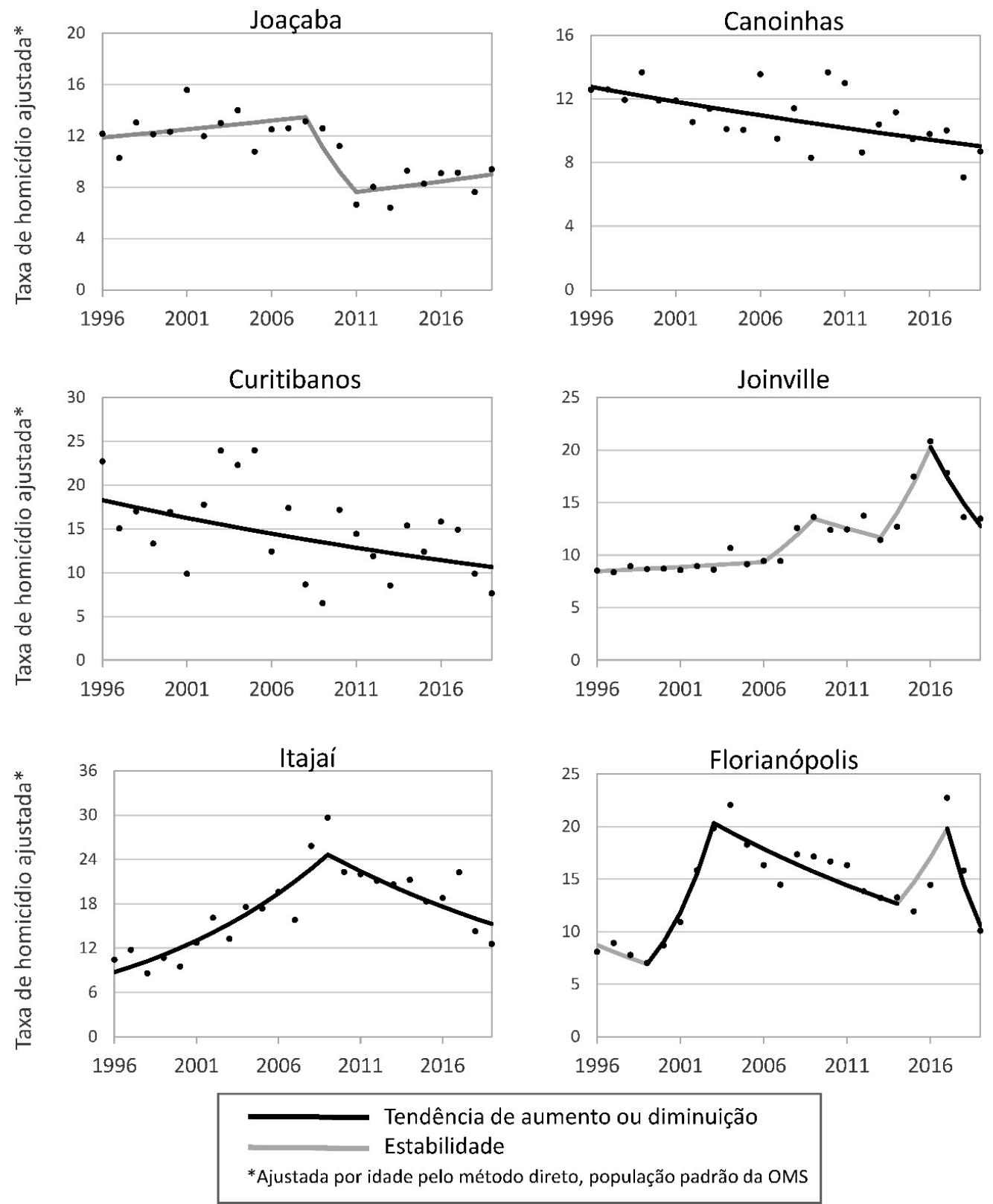

Figure 3. Tendência das taxas de homicídio nas microrregiões: Joaçaba, Canoinhas, Curitibanos, Joinville, Itajaí, Florianópolis 

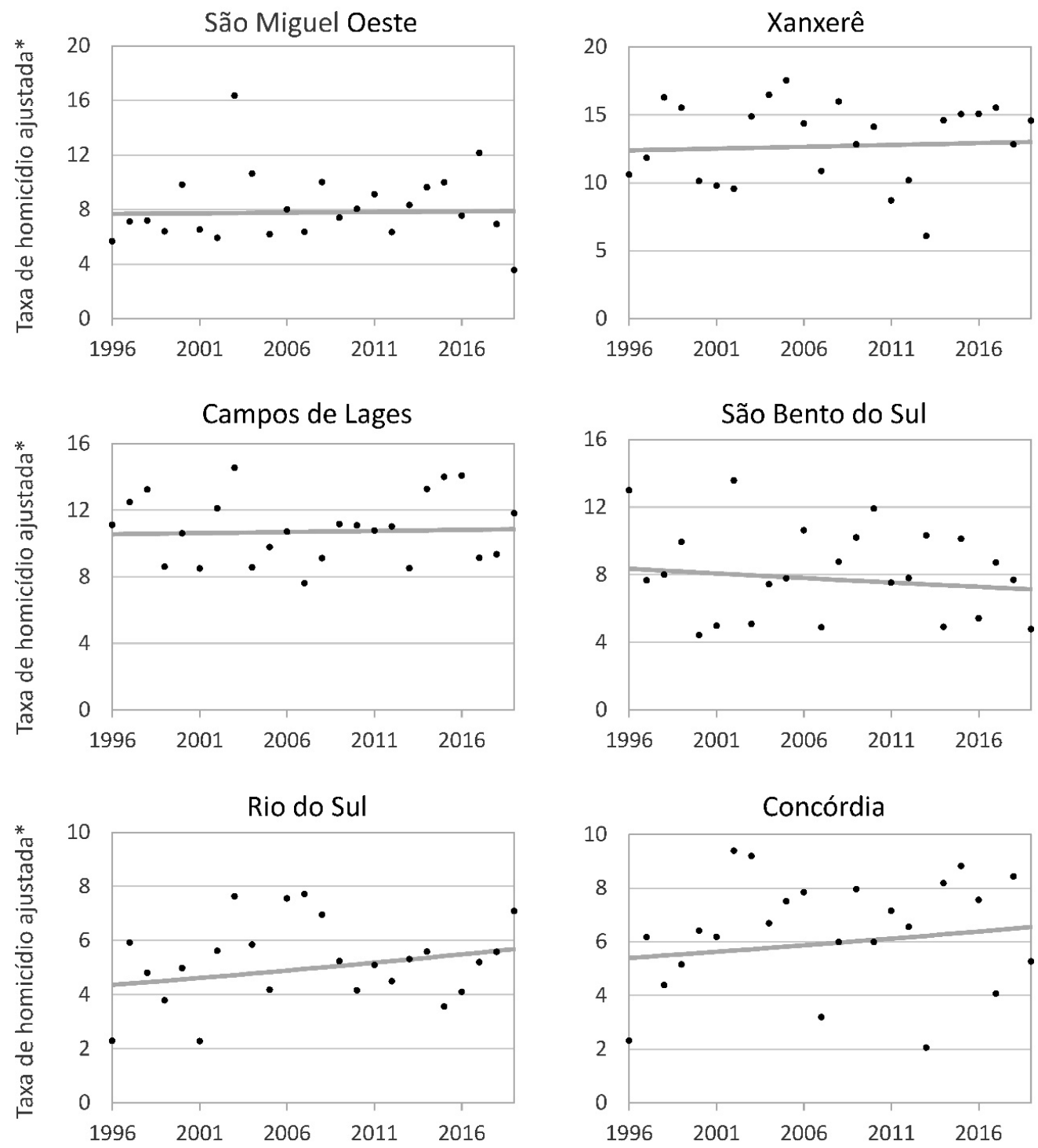

\section{Tendência de aumento ou diminuição Estabilidade \\ *Ajustada por idade pelo método direto, população padrão da OMS}

Figure 4. Tendência das taxas de homicídio nas microrregiões: São Miguel Oeste, Xanxerê, Campos de Lages, São Bento do Sul, Rio do Sul, Concórdia 
Table 1. Tendência das taxas de homicídio em Santa Catarina, por microrregião

\begin{tabular}{|c|c|c|c|}
\hline \multirow[t]{2}{*}{ Área } & Período & VPA $^{+}$ & IC $95 \%$ \\
\hline & $1996-2000$ & $-2,4$ & $(-8,2$ a 3,7$)$ \\
\hline \multirow[t]{3}{*}{ Santa Catarina } & $\angle U V u-\angle U v J$ & $+11,7$ & $(-7,9$ a 35,6$)$ \\
\hline & $2003-2017$ & $+1,3 *$ & $(0,3$ a 2,3$)$ \\
\hline & $2017-2019$ & $-13,6$ & $(-28,8$ a 4,9$)$ \\
\hline São Miguel Oeste & $1996-2019$ & $+0,1$ & $(-1,8$ a 2$)$ \\
\hline \multirow{2}{*}{ Chaneró } & $1996-2016$ & $+2,2 *$ & $(1,2$ a 3,2$)$ \\
\hline & $2016-2019$ & $-19,7 *$ & $(-33 \mathrm{a}-3,9)$ \\
\hline \multirow[t]{2}{*}{ Xanxerê } & $1996-2019$ & $+0,2$ & $(-1,4$ a 1,8$)$ \\
\hline & $1996-2008$ & $+1,1$ & $(-1$ a 3,2$)$ \\
\hline \multirow[t]{2}{*}{ Joaçaba } & $2008-2011$ & $-17,3$ & $(-41,9$ a 17,8$)$ \\
\hline & $2011-2019$ & $+2,1$ & $(-1,8$ a 6,1$)$ \\
\hline Concórdia & $1996-2019$ & $+0,8$ & $(-1,7$ a 3,4$)$ \\
\hline Canoinhas & $1996-2019$ & $-1,5 *$ & $(-2,3$ a $-0,6)$ \\
\hline \multirow[t]{3}{*}{ São Bento do Sul } & $1996-2019$ & $-0,7$ & $(-2,8$ a 1,4$)$ \\
\hline & $1996-2006$ & 1,0 & $(-0,6$ a 2,6$)$ \\
\hline & $2006-2009$ & 13,0 & $(-7,6$ a 38,1$)$ \\
\hline \multirow[t]{3}{*}{ Joinville } & $2009-2013$ & $-3,5$ & $(-12,7$ a 6,7$)$ \\
\hline & $2013-2016$ & $+20,2$ & $(-1,7$ a 47$)$ \\
\hline & $2016-2019$ & $-14,3 *$ & $(-22,5$ a $-5,2)$ \\
\hline Curitibanos & $1996-2019$ & $-2,3 *$ & $(-4,3 \mathrm{a}-0,3)$ \\
\hline Campos de Lages & $1996-2019$ & $+0,1$ & $(-1$ a 1,3$)$ \\
\hline Rio do Sul & $1996-2019$ & $+1,2$ & $(-0,8$ a 3,2$)$ \\
\hline Blumenau & $1996-2019$ & $+2,6^{*}$ & $(0,8$ a 4,5$)$ \\
\hline \multirow{2}{*}{ Itaiaí } & $1996-2009$ & $+8,3 *$ & $(5,8$ a 10,9$)$ \\
\hline & $2009-2019$ & $-4,7 *$ & $(-8 \mathrm{a}-1,3)$ \\
\hline \multirow[t]{3}{*}{ Ituporanga, Tijucas e Tabuleiro } & $1999-2019$ & $+5,4 *$ & $(2,2$ a 8,8$)$ \\
\hline & $1996-1999$ & $-7,5$ & $(-20,6$ a 7,9$)$ \\
\hline & $1999-2003$ & $+31,0 *$ & $(12,3$ a 52,7$)$ \\
\hline \multirow[t]{3}{*}{ Florianópolis } & $2003-2014$ & $-4,2 *$ & $(-6,5 \mathrm{a}-1,9)$ \\
\hline & $2014-2017$ & $+16,1$ & $(-14,6$ a 57,8$)$ \\
\hline & $2017-2019$ & $-27,1^{*}$ & $(-46,4$ a $-0,9)$ \\
\hline Tubarão & $1996-2019$ & $+4,4 *$ & $(2,6$ a 6,2$)$ \\
\hline \multirow{2}{*}{ Cricińma } & $1996-2015$ & $+7,4^{*}$ & $(4,6$ a 10,3$)$ \\
\hline & $2015-2019$ & $-13,3$ & $(-34,6$ a 15$)$ \\
\hline Araranguá & $1996-2019$ & $+2,7 *$ & $(0,6$ a 4,8$)$ \\
\hline
\end{tabular}

${ }^{+}$Variação Percentual Anual, *estatisticamente diferente de zero 


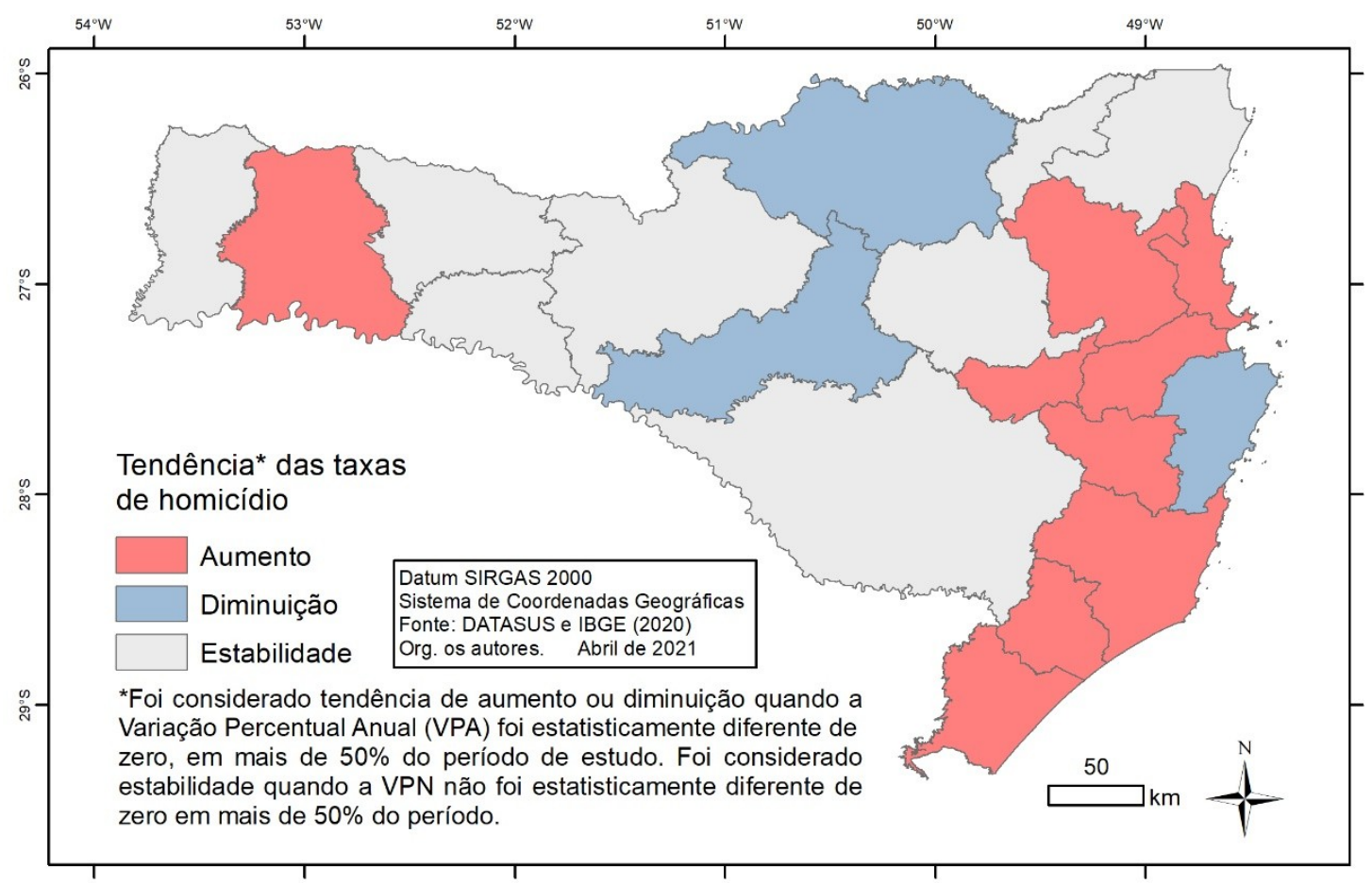

Figure 5. Tendência das taxas de homicídio em Santa Catarina, por microrregião

as microrregiões que apresentaram tendência de aumento do homicídio, em 71,4\% houve aumento da população urbana acima da média. Essa informação sugere possível associação do homicídio com a população em situação urbana, essa hipótese poderia ser testada posteriormente em áreas menores, como por município. Relatório da UNODC analisou a associação do homicídio com a população urbana em 68 cidades de todo o mundo, entre 2005 a 2016, e não foi identificada correlação positiva. O relatório destaca que cada cidade, até mesmo cada bairro, pode possuir fatores de risco específicos, portanto é preciso cautela na interpretação desses resultados (UNODC, 2019).

Com dados dos municípios brasileiros, Waiselfisz (2011) identificou em meados da década de 2000 um processo de desconcentração de homicídios nas capitais e regiões metropolitanas, e ao mesmo tempo um aumento nos municípios menores. De acordo com o autor, essa interiorização ou disseminação dos homicídios estaria relacionado com a emergência de novos polos econômicos em locais que não tinham aparelhos de segurança disponíveis. São Paulo e Rio de Janeiro, as duas maiores metrópoles do país, apresentaram tendência de diminuição das taxas de homicídio a partir de 2000 (Cardoso et al., 2016; M. F. Peres et al., 2011). Na cidade de São Paulo foram identificados grupos sociais onde a queda foi mais intensa: homens de 15 a 34, moradores de áreas de exclusão social, homicídios cometidos por arma de fogo. Essas informações sugerem associação dessa queda em função de mudança no padrão de violência comunitária e criminal como a questão do tráfico de drogas e atividades ilegais (M. F. Peres et al., 2011). Investimentos na área da segurança pública, como policiamento e aplicação da legislação de controlede 
armas (Goertzel \& Kahn, 2009), assim como o aumento do encarceramento (Nadanovsky, 2009) também foram elencadas como possíveis fatores explicativos. Inclui-se também a diminuição das desigualdades sociais, investimento em ações de educação e cultura (M. F. Peres et al., 2011). E por último, e não menos importante, mecanismos de controle do crime organizado, como a facção hegemônica Primeiro Comando da Capital (PCC) que atua de forma coordenada dentro e fora dos presídios. Feltran (2012) sugere a relação da implementação de políticas de interdição de atos violentos como o estupro e o homicídio com a queda dos homicídios em São Paulo. No Rio de Janeiro, Cardoso et al. (2016) sugerem possível associação da queda do homicídio com a implantação do Sistema Integrado de Metas (SIM) pelo governo do estado, e a implantação das Unidades de Polícia Pacificadora (UPP) em algumas localidades do município. Os autores destacam também um aumento expressivo nas taxas de pessoas desaparecidas, tanto no município quanto no estado do Rio de Janeiro.

A capital Recife também apresentou queda dos homicídios após alguns anos, em meados da década de 2000, com padrão espacial peculiar. Em alguns anos, os homicídios foram concentrados em 2,32\% das ruas do município (Pereira, Mota, \& Andresen, 2017). O estudo também identificou que a diminuição foi mais intensa nas ruas onde a concentração de homicídios era maior. Dentre os fatores relacionados os autores citam o Pacto pela Vida, uma política de segurança pública do estado de Pernambuco implantada em 2007, que resultou numa série de projetos com o objetivo de diminuir o homicídio. No entanto o estudo não fez uma análise aprofundada, com base empírica, sobre essa hipótese. No município de Itabuna na Bahia, Costa, Trindade, and Santos (2014) identificaram aumento da taxa de homicídio de 2000 a 2012, no entanto não testaram se o mesmo foi estatisticamente significativo. Os autores sugerem que esse aumento pode estar relacionado com a crise das lavouras cacaueiras na região, que gerou fluxo migratório dos trabalhadores para a cidade de Itabuna, sobretudo para a periferia da área urbana, onde concentram os homicídios. Portanto o homicídio apresenta padrões específicos, em diferentes escalas no tempo e no espaço.

Assim como a tendência de aumento do homicídio em Santa Catarina, de 2003 a 2017, encobriu diferenças regionais importantes, cada microrregião também pode encobrir diferenças entre municípios, bairros, setores censitários, ruas. No município de Chapecó, por exemplo, estudo identificou que todos os homicídios estavam concentrados em 1/3 dos bairros, no período de 2008 a 2015 (Monteiro \& Constante, 2018). É provável que a carga de homicídio no município de Chapecó tenha influenciado a tendência de aumento da microrregião. Há uma informação interessante revelada em nosso estudo, nos últimos anos as microrregiões Chapecó, Joinville e Florianópolis apresentaram tendência de queda brusca do homicídio, nos fazendo pensar em diferentes hipóteses para essa tendência, tais como: redução da desigualdade social, reflexo da inclusão de instituições de ensino e universidades públicas, investimento em cultura e lazer, promoção de cultura de paz e campanhas de desarmamento. Quais seriam outros possíveis desdobramentos dos resultados encontrados? Um dos caminhos seria uma análise mais detalhada do próprio fenômeno, ou seja, analisar também as taxas separadas por sexo, faixa etária, cor/raça, método de homicídio empregado. Outro caminho seria cruzar essas tendências com variáveis explicativas, provenientes de dados secundários, como renda, desemprego, e indicadores sintéticos como vulnerabilidade social, desorganização social (M. F. T. Peres \& Nivette, 2017). Diferentes metodologias também podem oferecer ganho de conhecimento, como informações coletadas em campo, em estudos etnográficos.

O presente estudo possui limitações, sendo a primeira inerente ao desenho do estudo ecológico. A falácia ecológica consiste em atribuir ao indivíduo associações encontradas em populações. O estudo 
ecológico tem baixo custo e pode ser o ponto de partida para novas pesquisas e hipóteses (Szklo \& Nieto, 2007). Outra limitação está relacionada com o registro de dados e eventuais erros de classificação na declaração de óbito. No entanto, este tipo de viés é inevitável em estudos sobre mortalidade por causas externas.

\section{CONSIDERAÇÕES FINAIS}

Nosso estudo identificou um aumento significativo das taxas de homicídio em Santa Catarina de 2003 a 2017. Ocorreram diferenças na dinâmica dos homicídios no estado de acordo com as microrregiões. Do total de áreas estudadas, $38,9 \%$ apresentaram tendência de aumento das taxas de homicídio, 16,7\% apresentaram tendência de diminuição e 44,4\% permaneceram estáveis. Os resultados indicam a necessidade de aprofundamento da investigação acerca desse cenário, favorecendo assim um monitoramento efetivo dos eventos, contribuindo assim para a formulação de políticas públicas intersetoriais que beneficiem a população.

\section{References}

Ahmad, O. B., Boschi-Pinto, C., Lopez, A., Murray, C., Lozano, R., \& Inoue, M. (2001). Retrieved from http://www.who.int/healthinfo/paper31.pdf

Bando, D. H., Jorge, M. H. P. M., Waldman, E. A., Volpe, F. M., \& Lester, D. (1904). Secular Trends of Suicide in the City of São Paulo. Crisis. Retrieved from 10.1027/0227-5910/a000816

Bando, D. H., \& Lester, D. (2014). An ecological study on suicide and homicide in Brazil. Cien Saude Colet, 19(4), 1179-1189. Retrieved from 10.1590/1413-81232014194.00472013

Cardoso, F. L. M. G., Cecchetto, F. R., Corrêa, J. S., \& Souza, T. O. (2016). Homicídios no Rio de Janeiro, Brasil: uma análise da violência letal. Ciência \& Saúde Coletiva, 21, 1277-1288. Retrieved from $10.1590 / 1413-81232015214.14712015$

Costa, F. A. D. M. M., Trindade, R. F. C., \& Santos, C. B. (2014). Deaths from homicides: a historical series. Revista Latino-Americana de Enfermagem, 22, 1017-1025. Retrieved from $10.1590 / 0104-1169.3603 .2511$

Datasus. (2021). Retrieved from http: / / www2.datasus.gov.br/DATASUS/index.php

Feltran, G. D. S. (1992). Governo que produz crime, crime que produz governo: o dispositivo de gestão do homicídio em São Paulo. Revista Brasileira de Segurança Pública, 6(2), 232-255.

Filho, A. M. S., Duarte, E. C., \& Merchan-Hamann, E. (2000). Trend and distribution of the homicide mortality rate in accordance with the size of the population of Brazilian municipalities - 2000 and. Cien Saude Colet, 25(3), 1147-1156. Retrieved from $10.1590 / 1413-81232020253$ .19872018

Global Mortality From Firearms. (1990). The Global Burden of Disease Injury Collaborators, 320 , 792-814. Retrieved from 10.1001/jama.2018.10060

Goertzel, T., \& Kahn, T. (2009). The Great São Paulo Homicide Drop. Homicide Studies, 13(4), 398-410.

Retrieved from $10.1177 / 1088767909348711$

(2019). Retrieved from http://surveillance.cancer.gov/joinpoint/

(2019). Retrieved from https://www. who.int/data/gho

Ibge. (2010). Retrieved from www . ibge.gov . br/

Ibge. (2021). Retrieved from https : / / www.ibge.gov.br 
Martinelli, M. (2013).

Monteiro, F. M., Constante, V., Hass, M., Matiello, A. M., Rotta, E., \& Seibel, . E. J. (2015). Violência e Segurança Pública em Chapecó: uma análise espacial e temporal das taxas de homicídios no período de 1980 a. Políticas públicas, descentralização e participação social: contribuições ao estudo da trajetória em Chapecó/SC,320-320. Retrieved from 10.24824 / 978854442992.1

Murray, J., Cerqueira, D. R., \& Kahn, T. (2013). Crime and violence in Brazil: Systematic review of time trends, prevalence rates and risk factors. Aggress Violent Behav, 18(5), 471-483. Retrieved from $10.1016 / j . a v b .2013 .07 .003$

Nadanovsky, P. (1996). O aumento no encarceramento e a redução nos homicídios em São Paulo, Brasil. Cadernos de Saúde Pública, 25, 1859-1864. Retrieved from 10.1590/S0102 $-311 \times 2009000800022$

Oliveira, A. L. S., Luna, C. F., \& Silva, M. (2020).

Homicídios do Brasil na última década: uma revisão integrativa, 25, 1925-1934. Retrieved from $10.1590 / 1413-81232020255.09932018$

Pereira, D. V. S., Mota, C. M. M., \& Andresen, M. A. (2017). The Homicide Drop in Recife, Brazil: A Study of Crime Concentrations and Spatial Patterns. Homicide Studies, 21(1), 21-38. Retrieved from $10.1177 / 1088767916634405$

Peres, M. F., Vicentin, D., Nery, M. B., Lima, R. S. D., Souza, E. R. D., Cerda, M., . . S (2011). Rev Panam Salud Publica, 29(1), 17-26.

Peres, M. F. T., Cardia, N., Neto, P. D. M., Santos, P. C., \& Adorno, S. (2008). Homicídios, desenvolvimento socioeconômico e violência policial no Município de São Paulo. Brasil. Revista Panamericana de Salud Pública, 23, 268-276.

Peres, M. F. T., \& Nivette, A. (2017). Social disorganization and homicide mortality rate trajectories in Brazil between 1991 and 2010. Soc Sci Med, 190, 92-100. Retrieved from 10.1016/ j.socscimed.2017.08.013

Reichenheim, M. E., Souza, E. R. D., Moraes, C. L., Jorge, M. H. D. M., Silva, C. M. D., Souza, D., \& Minayo, M. C. (2011). Violence and injuries in Brazil: the effect, progress made, and challenges ahead. Lancet, 377(9781), 60053-60056. Retrieved from 10 .1016/S0140-6736 (11) 60053 $-6$

Souza, M. D., Bernardi, L. D. S., \& Santos, J. A. (2020). Retrieved from http: / / www . scielo.br/ scielo.php?script=sci_arttext\&pid=S0020-38742020000300088\&nrm= iso

Szklo, M., \& Nieto, F. J. (2007). Jones and Bartlett Publishers. Retrieved from http: / / books . google.com.br/books?id=knc2tJa1NR0C

United Nations Office on Drugs and Crime. Global Study on Homicide. (2019). UNODC.

Valença, A. M., \& Moraes, T. M. D. (2006).

Braz J Psychiatry, 28(2), S62-68. Retrieved from 10.1590 /s1516-44462006000600003

Waiselfisz, J. J. (2011). Retrieved from http: / / www . mapadaviolencia.net.br/pdf2011/ MapaViolencia2011.pdf 